\title{
The Role of the Signaling Pathways Involved in the Protective Effect of Exogenous Hydrogen Sulfide on Myocardial Ischemia-Reperfusion Injury
}

\author{
Shuangyu Lv, Xiaotian Li, Shizhen Zhao, Huiyang Liu and Honggang Wang* \\ Henan International Joint Laboratory of Nuclear Protein Regulation, School of Basic Medical Sciences, Henan University, \\ Kaifeng, China
}

\section{OPEN ACCESS}

Edited by:

Wilson Kiiza Rumbeiha,

University of California, Davis,

United States

Reviewed by:

Claudia Penna,

University of Turin, Italy

Manish Kumar Gupta,

University of Central Florida,

United States

${ }^{*}$ Correspondence:

Honggang Wang

whg197167@vip.henu.edu.cn

Specialty section:

This article was submitted to

Cellular Biochemistry,

a section of the journal

Frontiers in Cell and Developmental

Biology

Received: 10 June 2021 Accepted: 11 August 2021 Published: 30 August 2021

Citation:

LV S, LiX, Zhao S, Liu H and Wang $H$ (2021) The Role of the

Signaling Pathways Involved

in the Protective Effect of Exogenous

Hydrogen Sulfide on Myocardial

Ischemia-Reperfusion Injury.

Front. Cell Dev. Biol. 9:723569.

doi: 10.3389/fcell.2021.723569
Ischemia/reperfusion $(I / R)$ injury refers to the functional and structural changes in the process of blood flow recovery after ischemia. In addition to ischemia, the blood flow recovery can also lead to very harmful damage, such as the obvious cell swelling and the irreversible cell necrosis. I/R injury is related with many diseases, including myocardial I/R injury. Myocardial I/R injury refers to the aggravation of ischemic myocardial tissue injury due to sudden disorder of blood circulation. Although there are many studies on myocardial I/R injury, the exact mechanism is not fully understood. Hydrogen sulfide $\left(\mathrm{H}_{2} \mathrm{~S}\right)$, like carbon monoxide and nitric oxide, is an important gas signal molecule. It plays an important role in many physiological and pathological processes. Recent studies indicate that $\mathrm{H}_{2} \mathrm{~S}$ can improve myocardial I/R injury, however, its mechanism is not fully understood, especially the involved signal pathways. In this review, we summarize the related researches about the role of the signaling pathways involved in the protective effects of exogenous $\mathrm{H}_{2} \mathrm{~S}$ on myocardial I/R injury, so as to provide theoretical reference for the future in-depth researches.

Keywords: hydrogen sulfide, myocardial ischemia/reperfusion injury, apoptosis, signaling pathways, antioxidant

\section{INTRODUCTION}

Ischemia/reperfusion (I/R) injury is used to describe the functional and structural damages which become apparent when the blood flow is restored after a period of ischemia. In addition to the ischemia, the recovery of blood flow can leads to potentially very harmful effects, such as the cell necrosis, the notable cell swelling, and the uneven blood flow of all parts of the recovered tissues (Oliveira et al., 2018; Soares et al., 2019). I/R injury is composed of two important events. Ischemia, the first important event, is the limitation of the blood supply to the organ, usually due to an embolus blocking the blood supply of an artery. The second important event is reperfusion, that is, the restoration of blood flow and reoxygenation in the affected ischemic area, which may further leads to the excessive tissue deterioration and trigger the destructive inflammatory response 
(Yan et al., 2020; Figure 1). I/R injury plays an important role in many diseases, such as heart diseases (Deguchi et al., 2020), brain diseases (Zhong et al., 2012), and liver diseases (Lin et al., 2020). Myocardial ischemia is a common phenomenon of coronary heart diseases. Myocardial I/R injury refers to the phenomenon that the injury of ischemic myocardial tissue becomes more serious due to the sudden disturbance of blood circulation (Lindsey et al., 2018). Although the researches on myocardial ischemia-reperfusion injury has been very extensive (Boag et al., 2017; Russo et al., 2017; Mokhtari-Zaer et al., 2018), its exact mechanism has not been fully understood.

Hydrogen sulfide $\left(\mathrm{H}_{2} \mathrm{~S}\right)$, which has the smell of rotten eggs, is a toxic, colorless and corrosive gas. Structurally, it is a sulfur analog of water molecules and can be oxidized to elemental sulfur, sulfate $\left(\mathrm{SO}_{4}{ }^{2-}\right)$, sulfur dioxide $\left(\mathrm{SO}_{2}\right)$, and thiosulfate $\left(\mathrm{S}_{2} \mathrm{O}^{3-}\right)$ (Murphy et al., 2019). $\mathrm{H}_{2} \mathrm{~S}$ was regarded as an environmental toxin until it was found to be endogenous (Paul and Snyder, 2018). In recent years, $\mathrm{H}_{2} \mathrm{~S}$, along with nitric oxide (NO) and carbon monoxide (CO), is the intracellular signal transduction molecules. It has been found that the low concentration of $\mathrm{H}_{2} \mathrm{~S}$ plays an vital role in the physiological process (Olas, 2015). Three enzymes have been found to catalyze the production of endogenous $\mathrm{H}_{2} \mathrm{~S}$ : cystathionine $\beta$-synthase (CBS), cystathionine $\gamma$-lyase (CSE), and 3-mercaptopyruvate sulfurtransferase (3MST) (Mustafa et al., 2009; Li et al., 2011; Wallace and Wang, 2015). CBS catalyzed the $\beta$-substitution of homocysteine with serine to produce L-cystathionine. CSE catalyzes the elimination of $\alpha, \gamma$ - cysteine of cystathionine to produce cystine. Under the catalysis of CBS and CSE, cysteine can produce $\mathrm{H}_{2} \mathrm{~S}$ through the $\beta$ eliminate reaction. Aminotransferase catalyzes cystine to transfer amine to $\alpha$ Ketoglutarate to form 3-mercaptopyruvic acid (3-MP). The sulfur of 3-MP was catalyzes by 3-MST to convert into $\mathrm{H}_{2} \mathrm{~S}$ (Wang et al., 2020; Figure 2). It has been reported that $\mathrm{H}_{2} \mathrm{~S}$ plays an important biological role in many human systems, such as respiratory system, cardiovascular system, endocrine system, nervous system, immune system, and gastrointestinal system (Gotor et al., 2019). In recent years, there are many studies on the effects of $\mathrm{H}_{2} \mathrm{~S}$ on myocardial I/R injury. However, its mechanism is not fully clear, especially the involved signal pathways. Therefore, we summarize the relevant researches about the above aspects to provide theoretical references for the future in-depth researches.

\section{THE ROLE OF JAK2/STAT3 SIGNALING PATHWAY INVOLVED IN THE PROTECTIVE EFFECT OF EXOGENOUS $\mathrm{H}_{2} \mathrm{~S}$ ON MYOCARDIAL I/R INJURY}

The Janus kinase/signal transducer and activator of transcription (JAK/STAT) signaling pathway is activated by a variety of interferons and cytokines, and widely involved in the tumor signal transduction. JAK is activated by the bingding of cytokines to its specific receptors of the cell membrane, which induces STAT phosphorylation. The phosphorylated STAT binds to the specific DNA elements and promotes the gene transcription (Murray, 2007). The JAK/STAT signaling pathway has been reported to be invoved in the innate and adaptive immunity, cells proliferation, tissues growth, angiogenesis and protease expression, and angiogenesis (Kiu and Nicholson, 2012; Yu et al., 2014). The JAK2/STAT3 signaling pathway has been demonstrated to play an important role in many kinds of heart diseases (Geng et al., 2019; Zhang J. et al., 2020), including myocardial I/R injury (Yin et al., 2020; Zhang Y. et al., 2020, however, the relevant mechanisms are not fully understood. Heng Fei Luan and colleagues found that NaHS (a donor of $\mathrm{H}_{2} \mathrm{~S}$ ) postconditioning attenuated the rat myocardial I/R injury by improving systemic hemodynamics, reducing myocardial infarct size and inhibiting cardiomyocyte apoptosis. While AG-490, a JAK2 inhibitor, abolished the cardioprotective effect of exogenous $\mathrm{H}_{2} \mathrm{~S}$. The in depth researches showed that NaHS postconditioning increased the expression of p-STAT3 and bcl-2, and decreased bax expression in the rat heart with I/R injury, while AG-490 counteracted these changes. Therefore, it can be deduced that $\mathrm{H}_{2} \mathrm{~S}$ postconditioning protected the rat hearts against I/R injury through JAK2/STAT3 signaling pathway (Luan et al., 2012). Rapamycin, an autophagy activator, has been reported to attenuate myocardial I/R injury by opening mitochondrial $K_{A T P}$ channel (Das et al., 2012), suggesting $\mathrm{K}_{A T P}$ channel is vital in myocardial $\mathrm{I} / \mathrm{R}$ injury. Exogenous $\mathrm{H}_{2} \mathrm{~S}$ can improve myocardial injury through opening $\mathrm{K}_{\text {ATP }}$ channel (Ji et al., 2008; Sun et al., 2015; Zhong et al., 2010), therefore, the relationship between JAK2/STAT3 signaling pathway and $\mathrm{K}_{A T P}$ channel in the protective effects of $\mathrm{H}_{2} \mathrm{~S}$ on myocardial I/R injury is worthy of further study. Studies revealed that STAT3 played the cardioprotection role through scavenging oxidants (Lei et al., 2019). Therefore, whether exogenous $\mathrm{H}_{2} \mathrm{~S}$ can alleviate myocardial I/R injury by eliminating oxidants through JAK2/STAT3 signaling pathway remains to be studied.

\section{THE ROLE OF Nrf2 SIGNALING PATHWAY INVOLVED IN THE PROTECTIVE EFFECT OF EXOGENOUS $\mathrm{H}_{2}$ S ON MYOCARDIAL I/R INJURY}

Nrf2 [nuclear factor (erythroid-derived 2)-like 2] is a transcription factor and is inhibited by interacting with the redox sensitive protein Kelch-like ECH-associated protein 1 (Keap1). Nrf2 is the main regulator of a group of antioxidant response elements containing cell protective genes induced in the stress response. It has been reported that $\mathrm{H}_{2} \mathrm{~S}$ improves diabetes-accelerated atherosclerosis by suppressing oxidative stress via Keap1 sulfhydrylation at Cys151 to activate Nrf2 signaling (Xie et al., 2016). $\mathrm{H}_{2} \mathrm{~S}$ also alleviates doxorubicininduced myocardial fibrosis through inhibiting oxidative stress and apoptosis via Keap1-Nrf2 (Li Y. et al., 2021). Extracellular signal-regulated kinase (ERK), also known as MAPK, plays vital role in the proliferation, differentiation, and survival (Rai et al., 2019). It has been reported that $\mathrm{H}_{2} \mathrm{~S}$ protects $\mathrm{H} 9 \mathrm{C} 2$ cardiac 


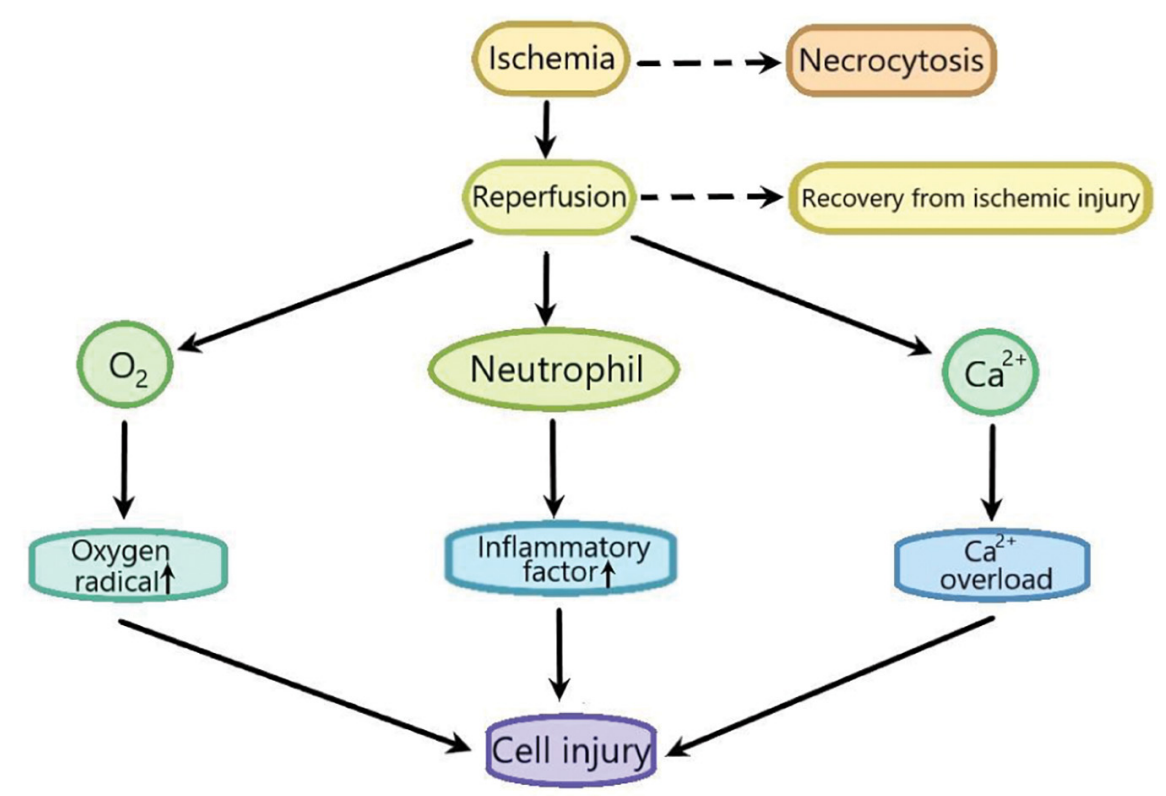

FIGURE 1 | The sketch of the process of ischemia-reperfusion injury. Ischemia leads to cell necrocytosis. Reperfusion induces a large amount of Ca ${ }^{2+}$ influx to lead $\mathrm{Ca}^{2+}$ overload which causes the cell injury. Reperfusion also induces the production of excessive oxygen free radicals, promotes the accumulation of pro-inflammatory factors such as neutrophils, and finally aggravates cell injury.

cells against high glucose-induced injury via p38 MAPK and ERK1/2 pathways (Xu et al., 2013). So far, there are few reports on $\mathrm{H}_{2} \mathrm{~S}$ improving myocardial I/R injury by activating Nrf2. The results of Peake et al. (2013) showed that the activities of three $\mathrm{H}_{2} \mathrm{~S}$ producing enzymes (CBS, CSE, and 3-MST) in the heart of diabetic mice were reduced. The levels of free $\mathrm{H}_{2} \mathrm{~S}$ and sulfane sulfur also were notably decreased in the heart and the blood of diabetic mice. Treatment with $\mathrm{H}_{2} \mathrm{~S}$ in the form of sodium sulfide $\left(\mathrm{Na}_{2} \mathrm{~S}\right) 24 \mathrm{~h}$ before myocardial ischemia ( $\mathrm{Na}_{2} \mathrm{~S}$ precondition) or 7 days before myocardial ischemia $\left(\mathrm{Na}_{2} \mathrm{~S} 7 \mathrm{~d}\right.$ precondition) could notably reduce rat diabetic myocardial I/R injury by decreasing infarct size. Moreover, the myocardial protective effect of $\mathrm{Na}_{2} \mathrm{~S} 7 \mathrm{~d}$ precondition was better than that of $\mathrm{Na}_{2} \mathrm{~S}$ PC. Pretreatment with $\mathrm{Na}_{2} \mathrm{~S}$ decreased the oxidative stress and the apoptosis induced by myocardial I/R injury through reducing lipid peroxidation levels and cleaved caspase-3, respectively, suggesting that $\mathrm{Na}_{2} \mathrm{~S}$ improve rat myocardial I/ $\mathrm{R}$ injury by inhibiting oxidative stress and the apoptosis. The mechanism researches revealed that $\mathrm{Na}_{2} \mathrm{~S}$ pretreatment activated $\mathrm{Nrf} 2$ signaling in rat diabetic myocardium with I/R injury, while diabetes impaired $\mathrm{Nrf} 2$ signaling. NQO1 and HO- 1 are important antioxidants. $\mathrm{Na}_{2} \mathrm{~S}$ $7 \mathrm{~d}$ PC increased the expression of NQO1 and heme oxygenase-1 (HO-1) by promoting Nrf2 binding to the promoter of NQO1 and HO-1. Bach1, a known HO-1 transcription inhibitor, which impeded the Nrf2 binding to $\mathrm{HO}-1$ promoter. The in depth researches showed that $\mathrm{Na}_{2} \mathrm{~S} 7 \mathrm{~d}$ PC could upregulate HO-1 expression by promoting the ERK1/2-dependent removal of Bach1 from the nucleus. Collectively, exogenous $\mathrm{H}_{2} \mathrm{~S}$ improved diabetic myocardial I/R injury by upregulating the expression of NQO1 and HO-1 through activating Nrf2 signaling

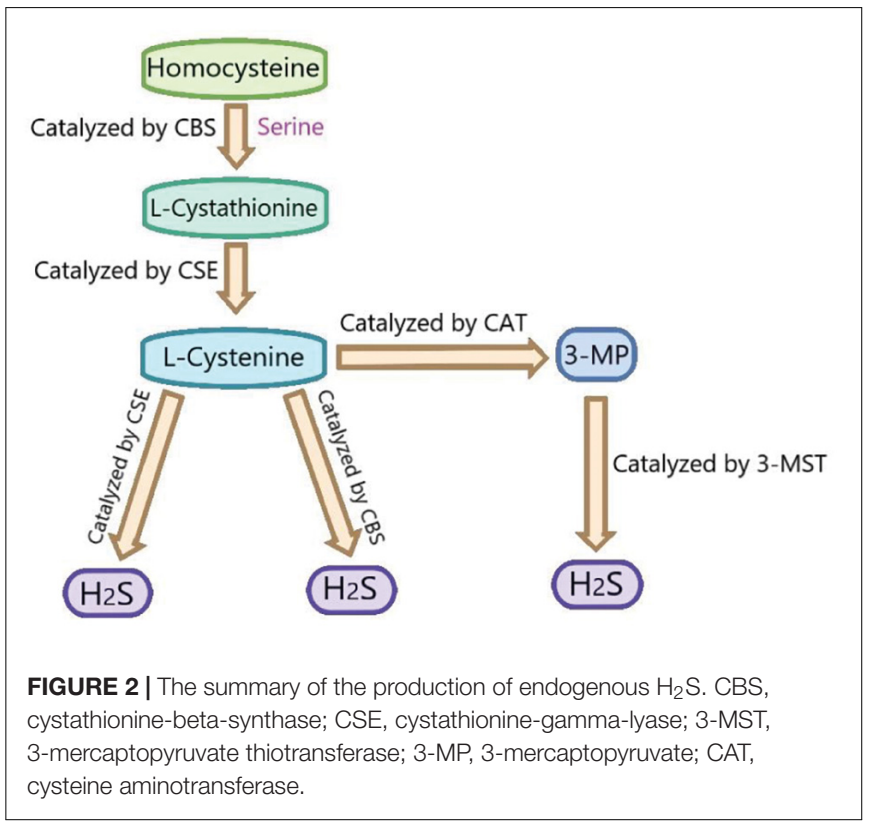

pathway in an ERK-dependent manner, which needs to be further confirmed with the inhibitor of Nrf2 signaling pathway (Peake et al., 2013). At present, there are few studies on the simultaneous activation of $\mathrm{Nrf} 2$ and ERK by $\mathrm{H}_{2} \mathrm{~S}$. Therefore, it is necessary to further study the mechanism of $\mathrm{H}_{2} \mathrm{~S}$ activation of $\mathrm{Nrf2/ERK}$. Increasing the level of $\mathrm{H}_{2} \mathrm{~S}$ in cardiomyocytes is a potential strategy to reduce myocardial $I / R$ injury in the setting of diabetes. 
TABLE 1 | The summary of exogenous hydrogen sulfide improvements of myocardial I/R injury.

\begin{tabular}{|c|c|c|c|}
\hline $\begin{array}{l}\text { The protective mode of myocardial } \\
\text { ischemia-reperfusion }(I / R) \text { injury }\end{array}$ & $\begin{array}{l}\text { The mechanism of } \mathrm{H}_{2} \mathrm{~S} \text { protection against } \\
\text { myocardial I/R injury }\end{array}$ & Experimental model & $\begin{array}{l}\text { The mode of } \mathrm{H}_{2} \mathrm{~S} \text { action } \\
\text { on myocardium }\end{array}$ \\
\hline $\begin{array}{l}\text { Exogenous } \mathrm{H}_{2} \mathrm{~S} \text { improves myocardial } \\
\text { I/R injury through JAK2/STAT3 signaling } \\
\text { pathway }\end{array}$ & Activating the JAK2/STAT3 signaling pathway & Rat myocardial I/R injury model & Postconditioning \\
\hline $\begin{array}{l}\text { Exogenous } \mathrm{H}_{2} \mathrm{~S} \text { protectes diabetic } \\
\text { mouse myocardial I/R injury through } \\
\text { activating Nrf2 signaling pathway in an } \\
\text { ERK-dependent manner }\end{array}$ & Activating the Nrf2/ERK signaling pathway & Rat myocardial I/R injury model & Preconditioning \\
\hline $\begin{array}{l}\text { Exogenous } \mathrm{H}_{2} \mathrm{~S} \text { alleviates myocardial } \\
\text { I/R injury in rats by activating } \\
\text { SIRT1/PGC-1 } \alpha \text { signaling pathway }\end{array}$ & Activating the SIRT1/PGC-1 $\alpha$ signaling pathway & Rat myocardial I/R injury model & Postconditioning \\
\hline $\begin{array}{l}\text { Exogenous } \mathrm{H}_{2} \mathrm{~S} \text { alleviated myocardial } \\
\text { I/R injury by inhibiting autophagy } \\
\text { through activating PI3K/SGK1/GSK3 } \beta \\
\text { signaling pathway }\end{array}$ & $\begin{array}{l}\text { Inhibiting autophagy through activating } \\
\text { PI3K/SGK1/GSK3 } \beta \text { signaling pathway }\end{array}$ & $\begin{array}{l}\text { The model of the neonatal rat } \\
\text { cardiomyocytes exposed to } \\
\text { hypoxia/reoxygenation }\end{array}$ & Preconditioning \\
\hline $\begin{array}{l}\text { Exogenous } \mathrm{H}_{2} \mathrm{~S} \text { alleviates myocardial } \\
\text { I/R injury through inhibiting JNK } \\
\text { signaling pathway }\end{array}$ & Inhibiting JNK signaling pathway & Rat myocardial I/R injury model & Postconditioning \\
\hline
\end{tabular}

\section{THE ROLE OF Sirt1/PGC-1 $\alpha$ SIGNALING PATHWAY INVOLVED IN THE PROTECTIVE EFFECT OF EXOGENOUS $\mathrm{H}_{2} \mathrm{~S}$ ON MYOCARDIAL I/R INJURY}

The silent information regulator of transcription 1 (SIRT1) is a highly conserved $\mathrm{NAD}^{+}$-dependent protein deacetylase, which deacetylates downstream peroxisome proliferator-activated receptor- $\gamma$ co-activator- $1 \alpha$ (PGC- $1 \alpha$ ) to promote its activity ( $\mathrm{Li}$ et al., 2016; Wang et al., 2018). The SIRT1/PGC-1 $\alpha$ signaling pathway has been demonstrated to participate in the regulation of many pathological processes related to cell survival, oxidative stress, intestinal homeostasis, and anti-aging (Hasegawa et al., 2008; Li et al., 2014; Wei et al., 2014). There are growing evidences that SIRT1/PGC-1 $\alpha$ signaling pathway is involved in myocardial I/R injury (Tang et al., 2019; Tian et al., 2019; Wang et al., 2019), however, the related mechanism is not fully clear. The results of Ming $\mathrm{Zhu} \mathrm{Hu}$ and colleagues showed that $\mathrm{H}_{2} \mathrm{~S}$ postconditioning alleviated the rat hearts $\mathrm{I} / \mathrm{R}$ injury by improving hemodynamic parameters, reducing the myocardial ischemia size, inhibiting the myocardial enzyme release, increasing ATP and superoxide dismutase (SOD) levels, and decreasing malondialdehyde (MDA) level. Exogenous $\mathrm{H}_{2} \mathrm{~S}$ also upregulated the expression of SIRT1 and PGC- $1 \alpha$ in the rat heart with I/R injury. EX-527, a selective SIRT1 inhibitor, reversed the above changes induced by $\mathrm{H}_{2} \mathrm{~S}$, suggesting that SIRT1/PGC-1 $\alpha$ signaling pathway mediated the protective effect of exogenous $\mathrm{H}_{2} \mathrm{~S}$ on myocardial I/R injury (Hu et al., 2016). The entry of SIRT1 into the nucleus is necessary for its cytoprotective effects against oxidative stress (Tanno et al., 2010), which may be invoved in the protective effect of $\mathrm{H}_{2} \mathrm{~S}$ on myocardial I/R injury. The in depth research showed that in rat cardiomyocyte, I/R induced SIRT1 out of the nucleus and this was reversed by exogenous $\mathrm{H}_{2} \mathrm{~S}$, which was the mechanism of exogenous $\mathrm{H}_{2} \mathrm{~S}$ activation of SIRT1/PGC- $1 \alpha$ signaling pathway. Collectively, Exogenous $\mathrm{H}_{2} \mathrm{~S}$ improves myocardial I/R injury in rats by activating SIRT1/PGC-1 $\alpha$ signaling pathway
(Hu et al., 2016). Studies have shown that high levels of $\mathrm{NAD}^{+}$, peroxisome proliferator activated receptor (PPAR), FOXO family transcription factors, and ubiquitination can regulate SIRT1 activity (Brunet et al., 2004; Kalliora et al., 2019; Chen et al., 2020; $\mathrm{Yu}$ et al., 2020). Therefore, whether exogenous $\mathrm{H}_{2} \mathrm{~S}$ can regulate SIRT1/PGC-1 $\alpha$ signaling pathway by the above substances needs further study.

\section{THE ROLE OF PI3K/SGK1/GSK3 $\beta$ SIGNALING PATHWAY INVOLVED IN THE PROTECTIVE EFFECT OF EXOGENOUS $\mathrm{H}_{2} \mathrm{~S}$ ON MYOCARDIAL I/R INJURY}

Phosphatidylinositol-3-kinase (PI3K) is a group of plasma membrane associated lipid kinases, which consists of three subunits (Donahue et al., 2012). It is involved in regulating proliferation, cell growth, and survival (Lee et al., 2011). The serum and glucocorticoid induced kinase-1 (SGK1) is a serine/threonine kinase widely expressed downstream of PI3K. SGK1 is ubiquitously expressed in various cell types (Lang et al., 2006, 2009). GSK3 $\beta$ is a vital downstream target of SGK1 and has been reported to alleviate myocardium I/R injury by regulating autophagy (Aoyama et al., 2005; Zhai et al., 2011). Jiang et al. (2016) found that the expression of t-PI3K, p-PI3K, t-SGK1, and p-SGK1 were decreased, the p-GSK3 $\beta$ expression was increased in cardiomyocyte exposed to hypoxia/reoxygenation $(\mathrm{H} / \mathrm{R})$, which were reversed by exogenous $\mathrm{H}_{2} \mathrm{~S}$, suggesting that exogenous $\mathrm{H}_{2} \mathrm{~S}$ activated PI3K/SGK1/GSK3 $\beta$ signaling pathway in cardiomyocyte with $H / R$ injury. The $H / R$ treatment of rat cardiomyocytes reduced cell viability, and aggravated cell injury by increasing LDH releasing, which were reversed by exogenous $\mathrm{H}_{2} \mathrm{~S}$. Further researches showed that autophagy was notably increased in cardiomyocytes exposed to $H / R$, which was reversed by exogenous $\mathrm{H}_{2} \mathrm{~S}$. The inhibition of PI3K with LY294002 (a PI3K inhibitor) or knocking down SGK1 with SGK1 
siRNA promoted autophagy and inhibited the anti-autophagy, and cardioprotective effects of exogenous $\mathrm{H}_{2} \mathrm{~S}$. While blocking GSK3 $\beta$ by tws119 (a GSK3 $\beta$ inhibitor) has the opposite effect. Collectively, it can be induced that exogenous $\mathrm{H}_{2} \mathrm{~S}$ alleviated myocardial I/R injury by inhibiting autophagy through activating PI3K/SGK1/GSK3 $\beta$ signaling pathway (Jiang et al., 2016). The relationship between $\mathrm{H}_{2} \mathrm{~S}$ and PI3K/SGK1/GSK3 $\beta$ signaling pathway, as well as the relationship between autophagy and PI3K/SGK1/GSK3 $\beta$ signaling pathway, has been rarely studied, which need further study.

\section{THE ROLE OF JNK SIGNALING PATHWAY INVOLVED IN THE PROTECTIVE EFFECT OF EXOGENOUS $\mathrm{H}_{2} \mathrm{~S}$ ON MYOCARDIAL I/R INJURY}

The c-Jun N-terminal kinases (JNKs) is a member of the mitogen activated protein kinase (MAPK) family and regulate the cell responses to a variety of exogenous and endogenous damages, including reactive oxygen species (ROS), radiation, DNA damage, bacterial antigens, heat, and inflammatory cytokines. In particular, the JNK signaling regulates many important physiological processes including metabolism and tissue homeostasis, cell damage repair and cell death/survival, and affects the life span of organisms (Tafesh-Edwards and Eleftherianos, 2020). The JNK signaling pathway is reported to be involved in myocardial I/R injury (Li A. et al., 2021; Yang et al., 2019). Li and Xiao (2020) found that the pretreatment with NaHS increased the left ventricular diastolic pressure (LVDP) and the maximum rate of pressure rise/fall, and decreased the left ventricular end-diastolic pressure (LVEDP) in rats with myocardial I/R injury. In the ischemia rats, the perinuclear space increased gradually, the arrangement of fibers was disordered, and the damage of the mitochondrial cristae and membrane was aggravated, which was reversed by exogenous $\mathrm{H}_{2} \mathrm{~S}$. The above suggested that exogenous $\mathrm{H}_{2} \mathrm{~S}$ notably improved myocardial I/R injury. The in-depth studies showed that in the cardiomyocytes with $\mathrm{I} / \mathrm{R}$ jury, exogenous $\mathrm{H}_{2} \mathrm{~S}$ also increased the endogenous $\mathrm{H}_{2} \mathrm{~S}$ level and induced the activity of CSE, SOD and GSH$\mathrm{Px}$, inhibited the activity of SOD, and reduced the level of phosphorylated JNK2. This indicated that exogenous $\mathrm{H}_{2} \mathrm{~S}$ may alleviate myocardial I/R injury through antioxidant and JNK signaling pathway (Li and Xiao, 2020), which need to be furthely conformed with the inhibitor of JNK signaling pathway. In addition, JNK signaling pathway is closely related to the oxidative stress (Yang et al., 2017; Chen et al., 2018; Xu et al., 2020), so whether exogenous $\mathrm{H}_{2} \mathrm{~S}$ can improve myocardial I/R injury by inhibiting oxidative stress through JNK signaling pathway is worthy of further study.

\section{CONCLUSION}

In this review, we summerized the signaling pathways involved in the protective effect of exogenous $\mathrm{H}_{2} \mathrm{~S}$ on myocardial I/R injury as follows: (1) exogenous $\mathrm{H}_{2} \mathrm{~S}$ postconditioning improves the rat myocardial I/R injury through JAK2/STAT3 signaling pathway; (2) exogenous $\mathrm{H}_{2} \mathrm{~S}$ protected diabetic mouse myocardial I/R injury through activating Nrf2 signaling pathway in an ERKdependent manner; (3) exogenous $\mathrm{H}_{2} \mathrm{~S}$ alleviates myocardial $\mathrm{I} / \mathrm{R}$ injury in rats by activating SIRT1/PGC-1 $\alpha$ signaling pathway; (4) exogenous $\mathrm{H}_{2} \mathrm{~S}$ alleviated myocardial I/R injury by inhibiting autophagy through activating PI3K/SGK1/GSK3 $\beta$ signaling pathway; and (5) exogenous $\mathrm{H}_{2} \mathrm{~S}$ alleviates myocardial I/R injury through inhibiting JNK signaling pathway (Table 1).

Hydrogen sulfide is now regarded as the third kind of signal gas transmitter after $\mathrm{NO}$ and $\mathrm{CO}$. It has a wide range of physiological and pathophysiological functions, including vasodilation, induction of angiogenesis, regulation of inflammatory response, regulation of glucose homeostasis, and regulation of neuronal activity. However, its role has not been fully studied. The mechanism of $\mathrm{H}_{2} \mathrm{~S}$ in the process of myocardial I/R injury remains to be further elucidated. For example, in addition to the signal pathways mentioned in this manuscript, is there any other signal pathway involved in the above effects? Can high concentration of $\mathrm{H}_{2} \mathrm{~S}$ aggravate myocardial I/R injury through the specific signaling pathways? In addition, the studies indicate that the cardioprotective effect of $\mathrm{H}_{2} \mathrm{~S}$ is related to gender. Estrogen can regulates the production and release of $\mathrm{H}_{2} \mathrm{~S}$ in cardiovascular cells to increase cell proliferation, cell migration, and vasodilation, which exert its cardiovascular protective effects (Teoh et al., 2020). The above related signal pathway mechanism needs to be clarified. $\mathrm{H}_{2} \mathrm{~S}$ can improve myocardial inflammation in diabetic mice by inhibiting NLRP3 inflammasome (Jia et al., 2020), I/R can cause inflammatory injury of tissue (Zhou et al., 2014), so whether $\mathrm{H}_{2} \mathrm{~S}$ can improve myocardial I/R injury by inhibiting NLRP3 inflammasome and the related signaling pathways deserve further study.

With the in-depth study of the signal pathway of $\mathrm{H}_{2} \mathrm{~S}$ in the process of myocardial I/R injury, the use of $\mathrm{H}_{2} \mathrm{~S}$ donor in the treatment of myocardial ischemia-reperfusion injury will become a very promising therapeutic strategy.

\section{AUTHOR CONTRIBUTIONS}

HW devised, wrote, and funded with the manuscript. SL wrote and funded with the manuscript. XL drew the figures. SZ and HL wrote the manuscript. All authors contributed to the article and approved the submitted version.

\section{FUNDING}

This work was supported by grants from key scientific and technological projects in Henan discipline construction funding project for HW, the Natural Science Foundation for Excellent Young Scholars of Henan Province (Grant No. 212300410026), the Program for Young Key Teacher of Henan Province (Grant No. 2020GGJS037), and the Youth Talent Promotion Plan of Henan Association for Science and Technology (Grant No. 2020HYTP054). 


\section{REFERENCES}

Aoyama, T., Matsui, T., Novikov, M., Park, J., Hemmings, B., and Rosenzweig, A. (2005). Serum and glucocorticoid-responsive kinase-1 regulates cardiomyocyte survival and hypertrophic response. Circulation 111, 1652-1659. doi: 10.1161/ 01.CIR.0000160352.58142.06

Boag, S. E., Andreano, E., and Spyridopoulos, I. (2017). Lymphocyte communication in myocardial ischemia/reperfusion injury. Antioxid. Redox. Signal 26, 660-675. doi: 10.1089/ars.2016.6940

Brunet, A., Sweeney, L. B., Sturgill, J. F., Chua, K. F., Greer, P. L., Lin, Y., et al. (2004). Stress-dependent regulation of FOXO transcription factors by the SIRT1 deacetylase. Science 303, 2011-2015. doi: 10.1126/science.1094637

Chen, C., Zhou, M., Ge, Y., and Wang, X. (2020). SIRT1 and aging related signaling pathways. Mech. Ageing Dev. 187:111215. doi: 10.1016/j.mad.2020.111215

Chen, Y., Feng, X., Hu, X., Sha, J., Li, B., Zhang, H., et al. (2018). Dexmedetomidine ameliorates acute stress-induced kidney injury by attenuating oxidative stress and apoptosis through inhibition of the ROS/JNK signaling pathway. Oxid. Med. Cell Longev. 2018:4035310. doi: 10.1155/2018/4035310

Das, A., Salloum, F. N., Durrant, D., Ockaili, R., and Kukreja, R. C. (2012). Rapamycin protects against myocardial ischemia-reperfusion injury through JAK2-STAT3 signaling pathway. J. Mol. Cell Cardiol. 53, 858-869. doi: 10.1016/ j.yjmcc.2012.09.007

Deguchi, H., Ikeda, M., Ide, T., Tadokoro, T., Ikeda, S., Okabe, K., et al. (2020). Roxadustat markedly reduces myocardial ischemia reperfusion injury in mice. Circ. J. 84, 1028-1033. doi: 10.1253/circj.CJ-19-1039

Donahue, T. R., Tran, L. M., Hill, R., Li, Y., Kovochich, A., Calvopina, J. H., et al. (2012). Integrative survival-based molecular profiling of human pancreatic cancer. Clin. Cancer Res. 18, 1352-1363. doi: 10.1158/1078-0432.CCR-111539

Geng, Z., Fan, W. Y., Zhou, B., Ye, C., Tong, Y., Zhou, Y. B., et al. (2019). FNDC5 attenuates obesity-induced cardiac hypertrophy by inactivating JAK2/STAT3associated inflammation and oxidative stress. J. Transl. Med. 17:107. doi: 10. 1186/s12967-019-1857-8

Gotor, C., Garcia, I., Aroca, A., Laureano-Marin, A. M., Arenas-Alfonseca, L., Jurado-Flores, A., et al. (2019). Signaling by hydrogen sulfide and cyanide through post-translational modification. J. Exp. Bot. 70, 4251-4265. doi: 10. 1093/jxb/erz225

Hasegawa, K., Wakino, S., Yoshioka, K., Tatematsu, S., Hara, Y., Minakuchi, H., et al. (2008). Sirt1 protects against oxidative stress-induced renal tubular cell apoptosis by the bidirectional regulation of catalase expression. Biochem. Biophys. Res. Commun. 372, 51-56. doi: 10.1016/j.bbrc.2008.04.176

Hu, M. Z., Zhou, B., Mao, H. Y., Sheng, Q., Du, B., Chen, J. L., et al. (2016). Exogenous hydrogen sul fi de postconditioning protects isolated rat hearts from ischemia/reperfusion injury through Sirt1/PGC-1alpha signaling pathway. Int. Heart J. 57, 477-482. doi: 10.1536/ihj.15-506

Ji, Y., Pang, Q. F., Xu, G., Wang, L., Wang, J. K., and Zeng, Y. M. (2008). Exogenous hydrogen sulfide postconditioning protects isolated rat hearts against ischemiareperfusion injury. Eur. J. Pharmacol. 587, 1-7. doi: 10.1016/j.ejphar.2008.03. 044

Jia, Q., Mehmood, S., Liu, X., Ma, S., and Yang, R. (2020). Hydrogen sulfide mitigates myocardial inflammation by inhibiting nucleotide-binding oligomerization domain-like receptor protein 3 inflammasome activation in diabetic rats. Exp. Biol. Med. (Maywood) 245, 221-230. doi: 10.1177/ 1535370219899899

Jiang, H., Xiao, J., Kang, B., Zhu, X., Xin, N., and Wang, Z. (2016). PI3K/SGK1/GSK3beta signaling pathway is involved in inhibition of autophagy in neonatal rat cardiomyocytes exposed to hypoxia/reoxygenation by hydrogen sulfide. Exp. Cell Res. 345, 134-140. doi: 10.1016/j.yexcr.2015.07.005

Kalliora, C., Kyriazis, I. D., Oka, S. I., Lieu, M. J., Yue, Y., Area-Gomez, E., et al. (2019). Dual peroxisome-proliferator-activated-receptor-alpha/gamma activation inhibits SIRT1-PGC1alpha axis and causes cardiac dysfunction. JCI Insight 5:e129556. doi: 10.1172/jci.insight.129556

Kiu, H., and Nicholson, S. E. (2012). Biology and significance of the JAK/STAT signalling pathways. Growth Fact. 30, 88-106. doi: 10.3109/08977194.2012. 660936

Lang, F., Artunc, F., and Vallon, V. (2009). The physiological impact of the serum and glucocorticoid-inducible kinase SGK1. Curr. Opin. Nephrol. Hypert. 18, 439-448. doi: 10.1097/MNH.0b013e32832f125e
Lang, F., Bohmer, C., Palmada, M., Seebohm, G., Strutz-Seebohm, N., and Vallon, V. (2006). (Patho)physiological significance of the serum- and glucocorticoidinducible kinase isoforms. Physiol. Rev. 86, 1151-1178. doi: 10.1152/physrev. 00050.2005

Lee, J. Y., Chiu, Y. H., Asara, J., and Cantley, L. C. (2011). Inhibition of PI3K binding to activators by serine phosphorylation of PI3K regulatory subunit p85alpha Src homology-2 domains. Proc. Natl. Acad. Sci. U.S.A. 108, 1415714162. doi: 10.1073/pnas.1107747108

Lei, S., Su, W., Xia, Z. Y., Wang, Y., Zhou, L., Qiao, S., et al. (2019). Hyperglycemiainduced oxidative stress abrogates remifentanil preconditioning-mediated cardioprotection in diabetic rats by impairing caveolin-3-modulated PI3K/Akt and JAK2/STAT3 signaling. Oxid. Med. Cell Longev. 2019:9836302. doi: 10. $1155 / 2019 / 9836302$

Li, A., Zhang, X., and Luo, Q. (2021). Neohesperidin alleviated pathological damage and immunological imbalance in rat myocardial ischemia-reperfusion injury via inactivation of JNK and NF-kappaB p65. Biosci. Biotechnol. Biochem. 85, 251-261. doi: 10.1093/bbb/zbaa064

Li, H. W., and Xiao, F. Y. (2020). Effect of hydrogen sulfide on cardiomyocyte apoptosis in rats with myocardial ischemia-reperfusion injury via the JNK signaling pathway. Eur. Rev. Med. Pharmacol. Sci. 24, 2054-2061. doi: 10.26355/ eurrev_202002_20383

Li, J., Feng, L., Xing, Y., Wang, Y., Du, L., Xu, C., et al. (2014). Radioprotective and antioxidant effect of resveratrol in hippocampus by activating Sirt1. Int. J. Mol. Sci. 15, 5928-5939. doi: 10.3390/ijms15045928

Li, L., Rose, P., and Moore, P. K. (2011). Hydrogen sulfide and cell signaling. Annu. Rev. Pharmacol. Toxicol. 51, 169-187. doi: 10.1146/annurev-pharmtox010510- 100505

Li, Y., Chandra, T. P., Song, X., Nie, L., Liu, M., Yi, J., et al. (2021). H2S improves doxorubicin-induced myocardial fibrosis by inhibiting oxidative stress and apoptosis via Keap1-Nrf2. Technol. Health Care 29, 195-209. doi: 10.3233/ THC-218020

Li, Y., Xu, S., Li, J., Zheng, L., Feng, M., Wang, X., et al. (2016). SIRT1 facilitates hepatocellular carcinoma metastasis by promoting PGC-1alphamediated mitochondrial biogenesis. Oncotarget 7, 29255-29274. doi: 10.18632/ oncotarget.8711

Lin, J., Huang, H. F., Yang, S. K., Duan, J., Qu, S. M., Yuan, B., et al. (2020). The effect of Ginsenoside Rg1 in hepatic ischemia reperfusion (I/R) injury ameliorates ischemia-reperfusion-induced liver injury by inhibiting apoptosis. Biomed. Pharmacother. 129, 110398. doi: 10.1016/j.biopha.2020.110398

Lindsey, M. L., Bolli, R., Canty, J. M. Jr., Du, X. J., Frangogiannis, N. G., Frantz, S., et al. (2018). Guidelines for experimental models of myocardial ischemia and infarction. Am. J. Physiol. Heart Circ. Physiol. 314, H812-H838. doi: 10.1152/ ajpheart.00335.2017

Luan, H. F., Zhao, Z. B., Zhao, Q. H., Zhu, P., Xiu, M. Y., and Ji, Y. (2012). Hydrogen sulfide postconditioning protects isolated rat hearts against ischemia and reperfusion injury mediated by the JAK2/STAT3 survival pathway. Braz. J. Med. Biol. Res. 45, 898-905. doi: 10.1590/s0100-879x2012007500090

Mokhtari-Zaer, A., Marefati, N., Atkin, S. L., Butler, A. E., and Sahebkar, A. (2018). The protective role of curcumin in myocardial ischemia-reperfusion injury. J. Cell Physiol. 234, 214-222. doi: 10.1002/jcp.26848

Murphy, B., Bhattacharya, R., and Mukherjee, P. (2019). Hydrogen sulfide signaling in mitochondria and disease. FASEB J. 33, 13098-13125. doi: 10.1096/ fj. $201901304 \mathrm{R}$

Murray, P. J. (2007). The JAK-STAT signaling pathway: input and output integration. J. Immunol. 178, 2623-2629. doi: 10.4049/jimmunol.178.5.2623

Mustafa, A. K., Gadalla, M. M., Sen, N., Kim, S., Mu, W., Gazi, S. K., et al. (2009). H2S signals through protein S-sulfhydration. Sci. Signal 2:ra72. doi: 10.1126/ scisignal.2000464

Olas, B. (2015). Hydrogen sulfide in signaling pathways. Clin. Chim. Acta 439, 212-218. doi: 10.1016/j.cca.2014.10.037

Oliveira, T. H. C., Marques, P. E., Proost, P., and Teixeira, M. M. M. (2018). Neutrophils: a cornerstone of liver ischemia and reperfusion injury. Lab. Invest. 98, 51-62. doi: 10.1038/labinvest.2017.90

Paul, B. D., and Snyder, S. H. (2018). Gasotransmitter hydrogen sulfide signaling in neuronal health and disease. Biochem. Pharmacol. 149, 101-109. doi: 10.1016/j. bcp.2017.11.019

Peake, B. F., Nicholson, C. K., Lambert, J. P., Hood, R. L., Amin, H., Amin, S., et al. (2013). Hydrogen sulfide preconditions the $\mathrm{db} / \mathrm{db}$ diabetic mouse heart 
against ischemia-reperfusion injury by activating Nrf2 signaling in an Erkdependent manner. Am. J. Physiol. Heart Circ. Physiol. 304, H1215-H1224. doi: 10.1152/ajpheart.00796.2012

Rai, S. N., Dilnashin, H., Birla, H., Singh, S. S., Zahra, W., Rathore, A. S., et al. (2019). The Role of PI3K/Akt and ERK in neurodegenerative disorders. Neurotox. Res. 35, 775-795. doi: 10.1007/s12640-019-0003-y

Russo, I., Penna, C., Musso, T., Popara, J., Alloatti, G., Cavalot, F., et al. (2017). Platelets, diabetes and myocardial ischemia/reperfusion injury. Cardiovasc. Diabetol. 16:71. doi: 10.1186/s12933-017-0550-6

Soares, R. O. S., Losada, D. M., Jordani, M. C., Evora, P., and Castro, E. S. O. (2019). Ischemia/reperfusion injury revisited: an overview of the latest pharmacological strategies. Int. J. Mol. Sci. 20:5034. doi: 10.3390/ijms20205034

Sun, Y., Huang, Y., Zhang, R., Chen, Q., Chen, J., Zong, Y., et al. (2015). Hydrogen sulfide upregulates KATP channel expression in vascular smooth muscle cells of spontaneously hypertensive rats. J. Mol. Med. (Berl.) 93, 439-455. doi: 10.1007/ s00109-014-1227-1

Tafesh-Edwards, G., and Eleftherianos, I. (2020). JNK signaling in Drosophila immunity and homeostasis. Immunol. Lett. 226, 7-11. doi: 10.1016/j.imlet.2020. 06.017

Tang, J., Lu, L., Liu, Y., Ma, J., Yang, L., Li, L., et al. (2019). Quercetin improve ischemia/reperfusion-induced cardiomyocyte apoptosis in vitro and in vivo study via SIRT1/PGC-1alpha signaling. J. Cell Biochem. 120, 9747-9757. doi: $10.1002 /$ jcb. 28255

Tanno, M., Kuno, A., Yano, T., Miura, T., Hisahara, S., Ishikawa, S., et al. (2010). Induction of manganese superoxide dismutase by nuclear translocation and activation of SIRT1 promotes cell survival in chronic heart failure. J. Biol. Chem. 285, 8375-8382. doi: 10.1074/jbc.M109.090266

Teoh, J. P., Li, X., Simoncini, T., Zhu, D., and Fu, X. (2020). Estrogen-mediated gaseous signaling molecules in cardiovascular disease. Trends Endocrinol. Metab. 31, 773-784. doi: 10.1016/j.tem.2020.06.001

Tian, L., Cao, W., Yue, R., Yuan, Y., Guo, X., Qin, D., et al. (2019). Pretreatment with Tilianin improves mitochondrial energy metabolism and oxidative stress in rats with myocardial ischemia/reperfusion injury via AMPK/SIRT1/PGC-1 alpha signaling pathway. J. Pharmacol. Sci. 139, 352-360. doi: 10.1016/j.jphs. 2019.02.008

Wallace, J. L., and Wang, R. (2015). Hydrogen sulfide-based therapeutics: exploiting a unique but ubiquitous gasotransmitter. Nat. Rev. Drug Discov. 14, 329-345. doi: 10.1038/nrd4433

Wang, C., Sun, X., Qiu, Z., and Chen, A. (2019). MiR-138-5p exacerbates hypoxia/reperfusion-induced heart injury through the inactivation of SIRT1PGC-1alpha. Inflamm. Res. 68, 867-876. doi: 10.1007/s00011-019-01268-2

Wang, H., Shi, X., Qiu, M., Lv, S., Zheng, H., Niu, B., et al. (2020). Hydrogen Sulfide Plays an Important Role by Influencing NLRP3 inflammasome. Int. J. Biol. Sci. 16, 2752-2760. doi: 10.7150/ijbs.47595

Wang, S., Wan, T., Ye, M., Qiu, Y., Pei, L., Jiang, R., et al. (2018). Nicotinamide riboside attenuates alcohol induced liver injuries via activation of SirT1/PGC1alpha/mitochondrial biosynthesis pathway. Redox. Biol. 17, 89-98. doi: 10. 1016/j.redox.2018.04.006

Wei, W., Li, L., Zhang, Y., Geriletu, Yang, J., Zhang, Y., et al. (2014). Vitamin C protected human retinal pigmented epithelium from oxidant injury depending on regulating SIRT1. ScientificWorldJournal 2014:750634. doi: 10.1155/2014/ 750634

Xie, L., Gu, Y., Wen, M., Zhao, S., Wang, W., Ma, Y., et al. (2016). Hydrogen sulfide induces keap1 S-sulfhydration and suppresses diabetes-accelerated atherosclerosis via Nrf2 activation. Diabetes 65, 3171-3184. doi: 10.2337/db160020

Xu, B. Y., Tang, X. D., Chen, J., Wu, H. B., Chen, W. S., and Chen, L. (2020). Rifampicin induces clathrin-dependent endocytosis and ubiquitin-proteasome degradation of MRP2 via oxidative stress-activated PKC-ERK/JNK/p38 and PI3K signaling pathways in HepG2 cells. Acta Pharmacol. Sin. 41, 56-64. doi: 10.1038/s41401-019-0266-0
Xu, W., Wu, W., Chen, J., Guo, R., Lin, J., Liao, X., et al. (2013). Exogenous hydrogen sulfide protects $\mathrm{H} 9 \mathrm{c} 2$ cardiac cells against high glucose-induced injury by inhibiting the activities of the p38 MAPK and ERK1/2 pathways. Int. J. Mol. Med. 32, 917-925. doi: 10.3892/ijmm.2013.1462

Yan, H. F., Tuo, Q. Z., Yin, Q. Z., and Lei, P. (2020). The pathological role of ferroptosis in ischemia/reperfusion-related injury. Zool. Res. 41, 220-230. doi: 10.24272/j.issn.2095-8137.2020.042

Yang, H., Xie, Y., Yang, D., and Ren, D. (2017). Oxidative stress-induced apoptosis in granulosa cells involves JNK, p53 and Puma. Oncotarget 8, 25310-25322. doi: 10.18632/oncotarget.15813

Yang, Z. H., Lu, Y. J., Gu, K. P., Xiang, Z. Y., and Huang, H. M. (2019). Effect of ulinastatin on myocardial ischemia-reperfusion injury through JNK and P38 MAPK signaling pathways. Eur. Rev. Med. Pharmacol. Sci. 23, 8658-8664. doi: 10.26355/eurrev_201910_19183

Yin, Q., Zhao, B., Zhu, J., Fei, Y., Shen, W., Liang, B., et al. (2020). JLX001 improves myocardial ischemia-reperfusion injury by activating Jak2-Stat3 pathway. Life Sci. 257:118083. doi: 10.1016/j.lfs.2020.118083

Yu, H., Lee, H., Herrmann, A., Buettner, R., and Jove, R. (2014). Revisiting STAT3 signalling in cancer: new and unexpected biological functions. Nat. Rev. Cancer 14, 736-746. doi: $10.1038 / \mathrm{nrc} 3818$

Yu, L., Dong, L., Li, H., Liu, Z., Luo, Z., Duan, G., et al. (2020). Ubiquitinationmediated degradation of SIRT1 by SMURF2 suppresses CRC cell proliferation and tumorigenesis. Oncogene 39, 4450-4464. doi: 10.1038/s41388-020-1298-0

Zhai, P., Sciarretta, S., Galeotti, J., Volpe, M., and Sadoshima, J. (2011). Differential roles of GSK-3beta during myocardial ischemia and ischemia/reperfusion. Circ. Res. 109, 502-511. doi: 10.1161/CIRCRESAHA.111.249532

Zhang, J., Sun, Z., Lin, N., Lu, W., Huang, X., Weng, J., et al. (2020). Fucoidan from Fucus vesiculosus attenuates doxorubicin-induced acute cardiotoxicity by regulating JAK2/STAT3-mediated apoptosis and autophagy. Biomed. Pharmacother. 130:110534. doi: 10.1016/j.biopha.2020.110534

Zhang, Y., Shi, K., Lin, T., Xia, F., Cai, Y., Ye, Y., et al. (2020). Ganoderic acid $\mathrm{A}$ alleviates myocardial ischemia-reperfusion injury in rats by regulating JAK2/STAT3/NF-kappaB pathway. Int. Immunopharmacol. 84:106543. doi: 10. 1016/j.intimp.2020.106543

Zhong, G. Z., Li, Y. B., Liu, X. L., Guo, L. S., Chen, M. L., and Yang, X. C. (2010). Hydrogen sulfide opens the KATP channel on rat atrial and ventricular myocytes. Cardiology 115, 120-126. doi: 10.1159/000260073

Zhong, L., Wang, Z. F., and Xiao, B. J. (2012). [Research on the antioxidant effect of Enshi banqiao radix codonopsis on brain ischemia/reperfusion (I/R)injury]. Zhongguo Ying Yong Sheng Li Xue Za Zhi 28, 314-316.

Zhou, F., Wang, L., Liu, P., Hu, W., Zhu, X., Shen, H., et al. (2014). Puerarin protects brain tissue against cerebral ischemia/reperfusion injury by inhibiting the inflammatory response. Neural Regen. Res. 9, 2074-2080. doi: 10.4103/16735374.147934

Conflict of Interest: The authors declare that the research was conducted in the absence of any commercial or financial relationships that could be construed as a potential conflict of interest.

Publisher's Note: All claims expressed in this article are solely those of the authors and do not necessarily represent those of their affiliated organizations, or those of the publisher, the editors and the reviewers. Any product that may be evaluated in this article, or claim that may be made by its manufacturer, is not guaranteed or endorsed by the publisher.

Copyright (c) $2021 \mathrm{Lv}, \mathrm{Li}$, Zhao, Liu and Wang. This is an open-access article distributed under the terms of the Creative Commons Attribution License (CC BY). The use, distribution or reproduction in other forums is permitted, provided the original author(s) and the copyright owner(s) are credited and that the original publication in this journal is cited, in accordance with accepted academic practice. No use, distribution or reproduction is permitted which does not comply with these terms. 